\title{
Modeling and analysis of vector control systems for asynchronous motor
}

\author{
Viktor Meshcheryakov ${ }^{1, *}$, Tatyana Sinyukova ${ }^{1}$, Vladislav Gladyshev ${ }^{1}$, Alexey Sinyukov ${ }^{1}$, Lyudmila Solovieva $^{1}$, Elena \\ Gracheva $^{2}$
}

${ }^{1}$ Electric Drive Department, Lipetsk State Technical University, Lipetsk, Russia

${ }^{2}$ Kazan State Power Engineering University, str. Krasnoselskaya, 51, 420066, Kazan, Russia

\begin{abstract}
At metallurgical enterprises, slab transfer devices are widely used, the principle of operation of which is to lift slabs in the steel casting area and transport them to the storage area. The article considers the existing control system of the slab transfer device. At the moment, the mechanism has a DC motor controlled by a thyristor Converter. This system is difficult to maintain and has a large size. As an upgrade, the installation of an asynchronous motor with a frequency Converter is proposed. In the Matlab environment, mathematical models of single-circuit and double-circuit DC motor control systems and a model of asynchronous motor with a short-circuited rotor have been developed. A vector control system is used as an AC motor control system. As a result of simulation performed analysis of the characteristics. As an optimization of the system with vector control, in order to reduce dynamic loads on the turntable, it is proposed to introduce an intensity setter into the system, the use of which provides the necessary restriction of accelerations and jerks, reduces shock loads on the mechanical components of the electric drive, including a reduction in the load on the turntable when lowering the slab.
\end{abstract}

\section{General information}

The article reviewed the existing device management system to transfer the slabs. As proposed upgrading plant asynchronous motor with frequency converter. As a result of simulation performed analysis of the characteristics.

UPS-9 consists of a bridge with a pincer grip moving in the working area of the UNRS, electrical equipment of the bridge and electrical equipment permanently located in the workshop.

At the facility, on the hoist drive, there is a parallel excitation DC electric drive of the D818U1 type. The motor is controlled by a thyristor converter.

A modern and reliable solution for hoist control systems is a frequency drive based on an asynchronous squirrel cage motor. The main advantages of its use are the reduction of costs and labor intensity in the process of servicing the electric drive, as well as wear of the mechanical and electrical equipment of the mechanism.

To simulate the UPS-9 electric drive system, the Simulink Matlab package was chosen [1-9]. The AC motor control system is a vector system with rotor flux linkage vector control. In the simulation, a complete mathematical model of asynchronous motors was used, written in the orthogonal coordinate system $\mathrm{x}, \mathrm{y}$. This coordinate system is fixed relative to the stator.

\subsection{System with DC motor (single circuit)}

Figure 1 shows the Model of the armature current loop of the D818U1 motor in Matlab Simulink.

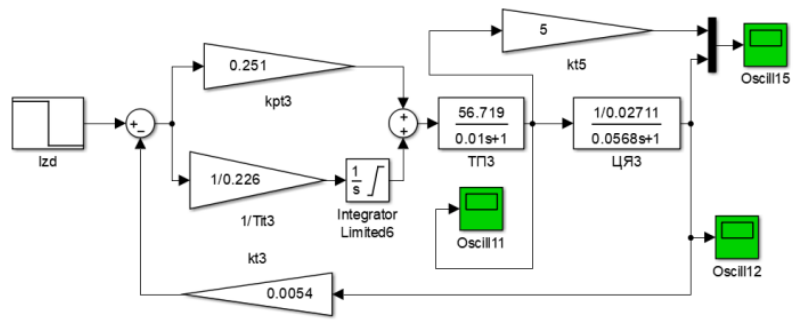

Fig. 1. Model of the armature current circuit of the D818U1 motor in Matlab Simulink.

\subsection{System with DC motor (dual circuit)}

Figure 2 shows a model of the dual-circuit control system of the D818U1 engine of the UPS-9 slab lifting mechanism.

Corresponding author: mesherek@yandex.ru 


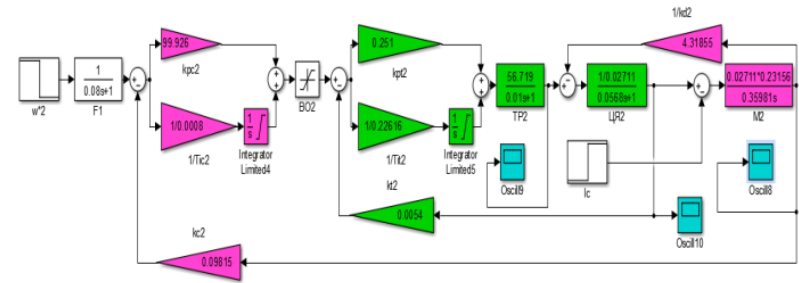

Fig. 2. Model of a dual-circuit engine control system D818U1.

\subsection{AC motor system}

The mathematical model of the UPS- 9 engine, created in the Matlab environment, is shown in Figure 3.

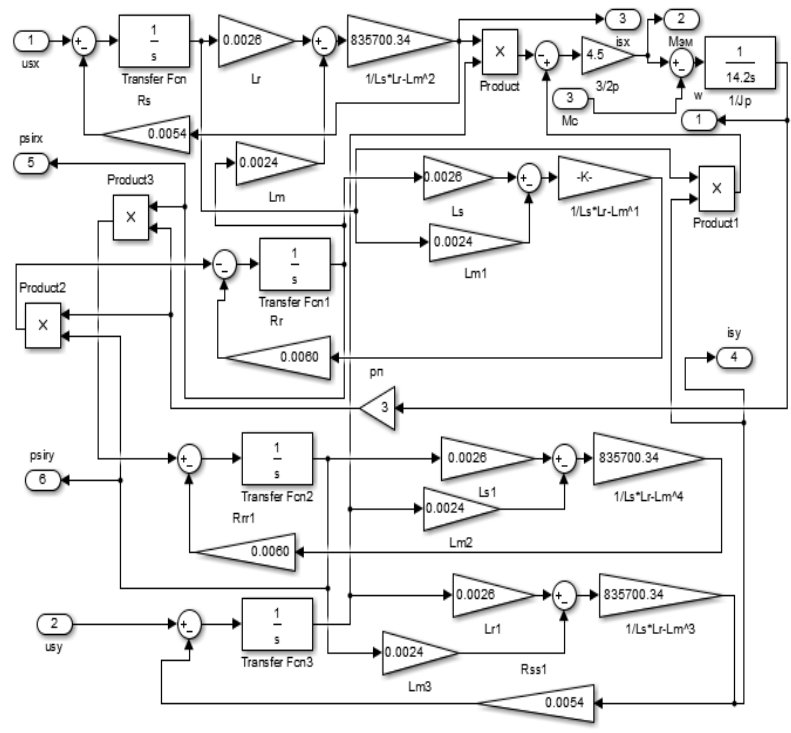

Fig. 3. Mathematical model of an IM with a short circuit rotor in a fixed coordinate system $x, y$ in the Matlab Simulink shell.

The speed reference for the electric drive system is carried out through the intensity generator, the model of which in the Matlab environment is shown in Figure 4.

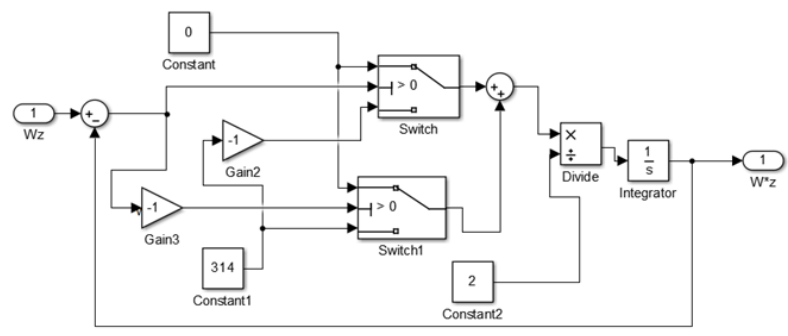

Fig. 4. Intensity generator block in Matlab.

The speed reference in accordance with the technical process was presented in the model as a block of step signal Step. The reference comes in the form of linear speed, and then, by means of simple transformations, the reference for the angular speed is supplied to the control system.

The VF block was used to convert the rotor flux linkage from real and imaginary variables into complex numbers and to convert the complex number to the magnitude of the flux linkage vector and its current angle in a fixed coordinate system (x,y). The content of the block is shown in Figure 5.

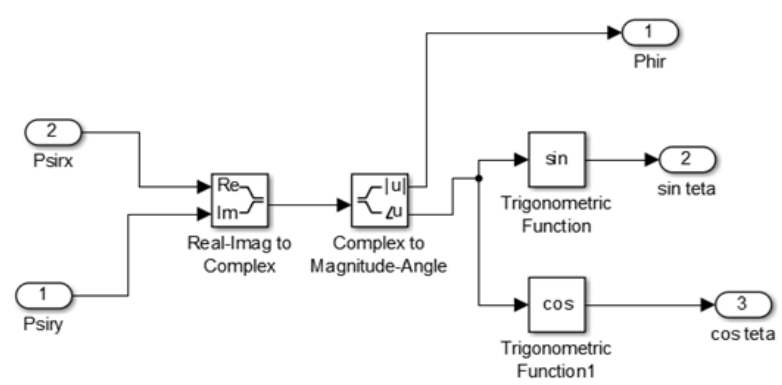

Fig. 5. VF block structure in Matlab environment.

The rotor flux linkage magnitude module is fed to the Phir output, and the angle is converted to sine or cosine for the UQ1 and UQ2 coordinate transformation blocks.

The UQ2 block converts the stationary coordinate system into a rotating one synchronously with the rotor flux linkage. The block structure is shown in Fig. 6 .

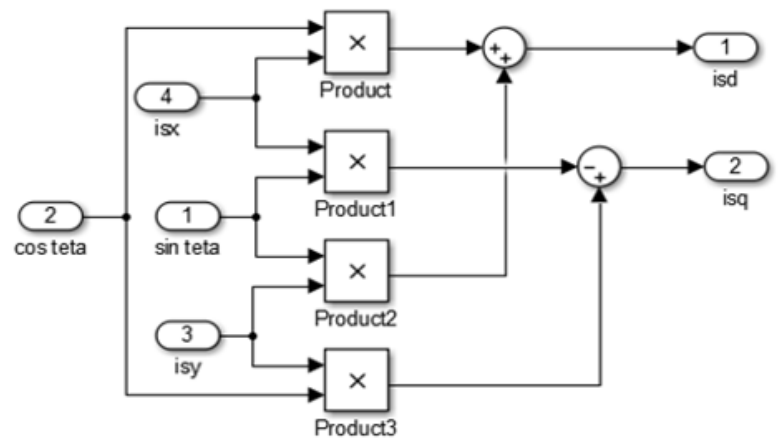

Fig. 6. Coordinate transformer structure.

The block for the inverse transformation is performed in the same way.

During the simulation, a complete mathematical model was used, therefore, it becomes necessary to use a compensation and circuit decoupling unit.

The block structure is shown in Fig. 7. 


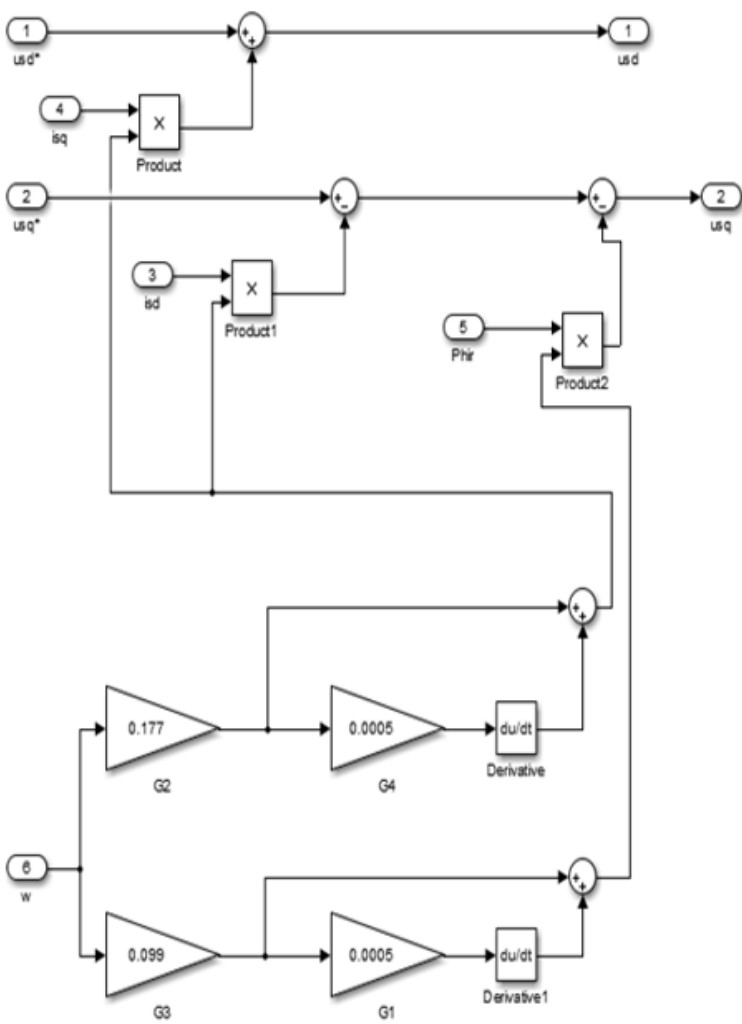

Fig. 7. Loop compensation and decoupling unit.

Figure 8 shows a mathematical model of an asynchronous electric drive with vector control and coordinate transformation in the Simulink Matlab software package.

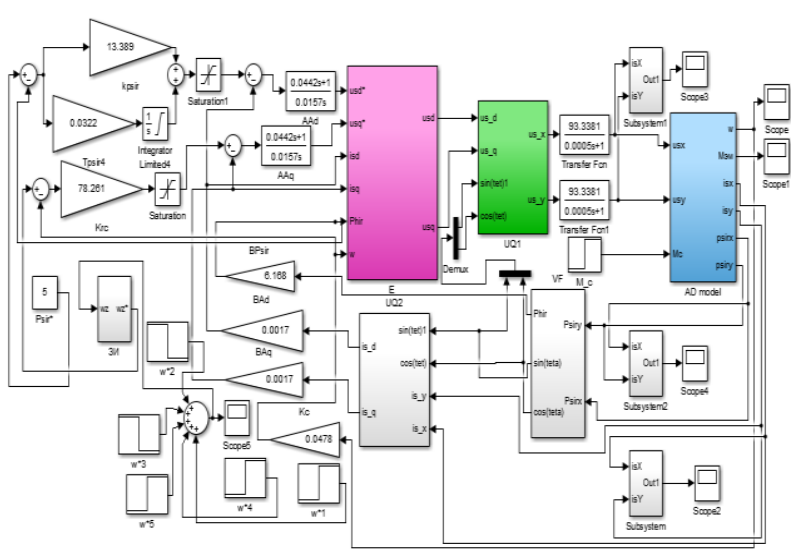

Fig. 8. Mathematical model of an asynchronous electric drive with vector control and coordinate transformation in the Simulink Matlab software package.

\section{Modeling}

\subsection{DC motor (single circuit system)}

Figures 9, 10 show the transient processes of the armature current and the converter emf without taking into account the back-emf of the D818U1 motor.

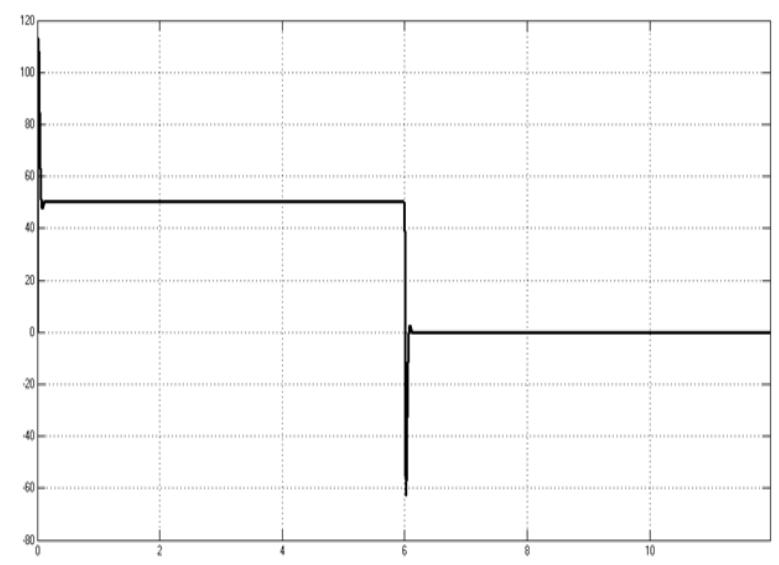

Fig. 9. Transient process of the emf of the converter without taking into account the counter-emf of the D818U1 motor in Matlab Simulink.

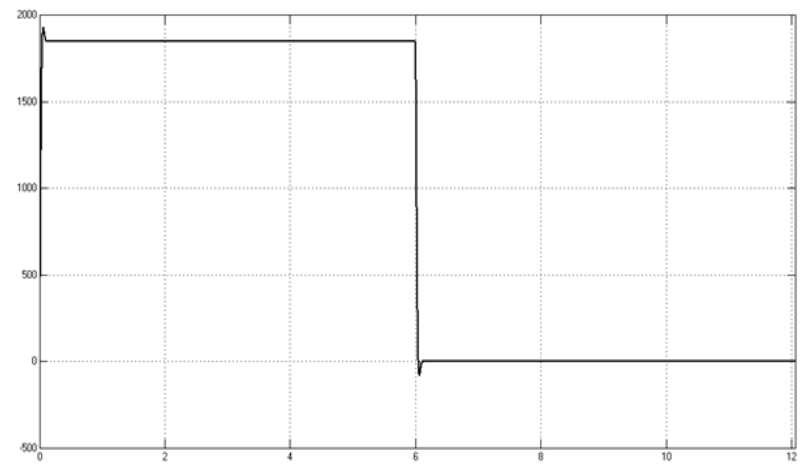

Fig. 10. Transient process of the armature current without taking into account the back-emf of the D818U1 motor in Matlab Simulink.

The overshoot error is no more than 5 percent, which corresponds to the adjustment of the armature current loop to the modular optimum.

\subsection{DC motor (dual circuit system)}

Graphs of transient processes in terms of speed $\omega=\mathrm{f}(\mathrm{t})$, current $I=f(t)$ and EMF of the converter $E=f(t)$ during operation with rated load are shown in Figures 11, 12 and 13 , respectively.

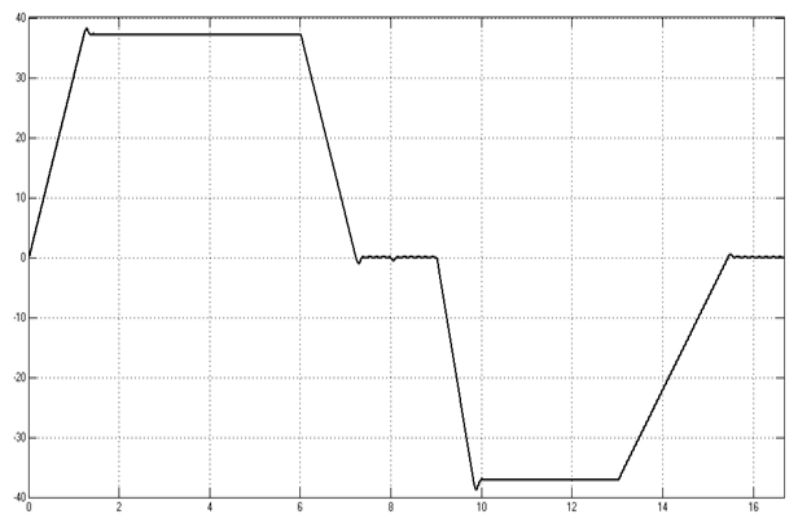

Fig. 11. Speed transient during slab lifting duty cycle in Matlab Simulink. 


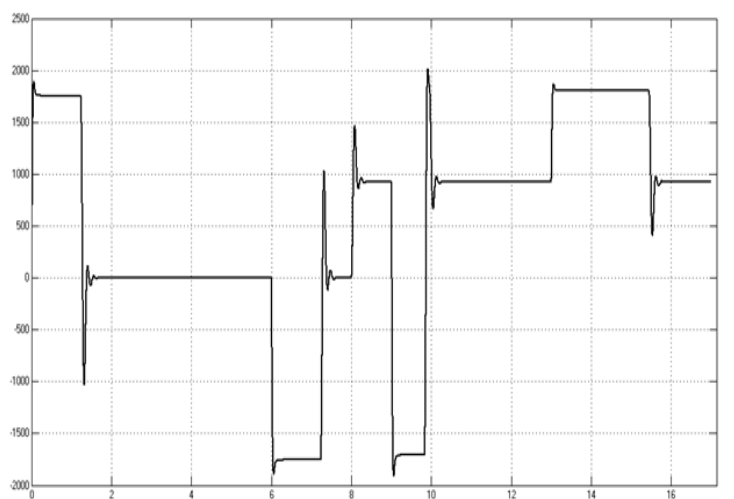

Fig. 12. Armature current transient in the slab lifting duty cycle in Matlab Simulink.

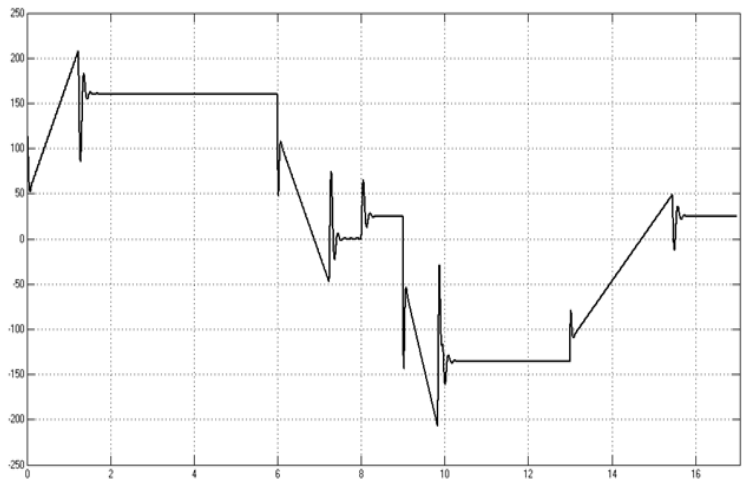

Fig. 13. Transient process on the EMF of the converter during the working cycle of lifting the slab in Matlab Simulink.

The voltage at the output of the thyristor converter rises at the moments of acceleration due to the need to compensate for the effect of the back-emf of the motor. The speed reference is processed without error under load, thus, it is possible to assert that the speed controller is set correctly. The given armature current is processed with an error of $90 \mathrm{~A}$.

\subsection{Asynchronous motor}

Figures 14 - 17 show, respectively, transient processes of speed $\omega=\mathrm{f}(\mathrm{t})$, torque $\mathrm{M}=\mathrm{f}(\mathrm{t})$, stator current $\mathrm{I}=\mathrm{f}(\mathrm{t})$ and flux linkage $\psi=\mathrm{f}(\mathrm{t})$ during the technological cycle of an asynchronous electric drive with vector control UPS-9.

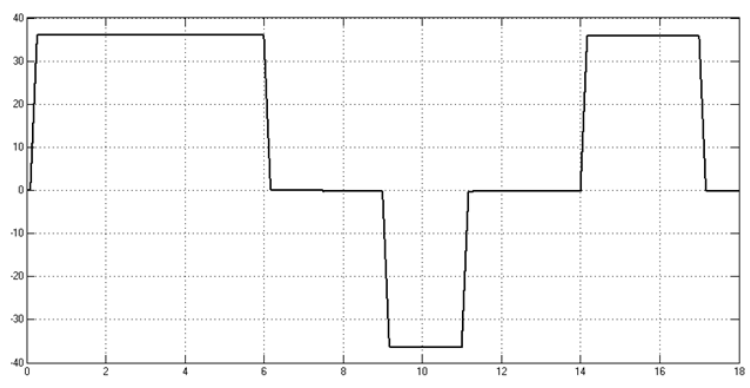

Fig. 14. The transient process of speed during the working cycle of an asynchronous electric drive with vector control in the Matlab Simulink shell.

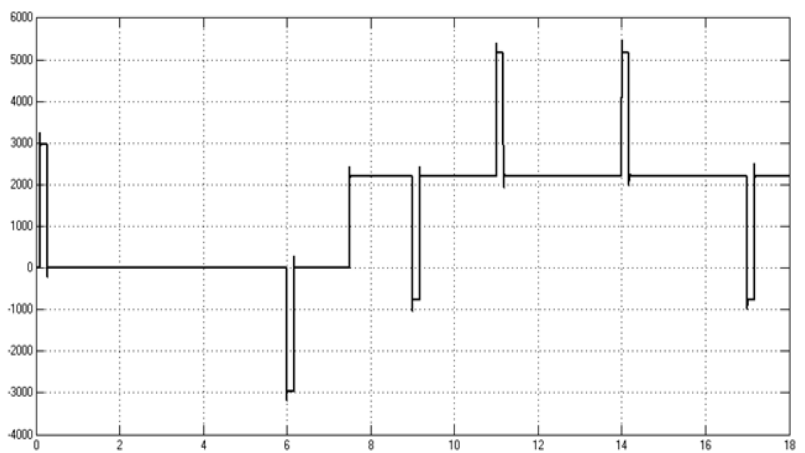

Fig. 15. Torque transient during the working cycle of an asynchronous electric drive with vector control in the Matlab Simulink shell.

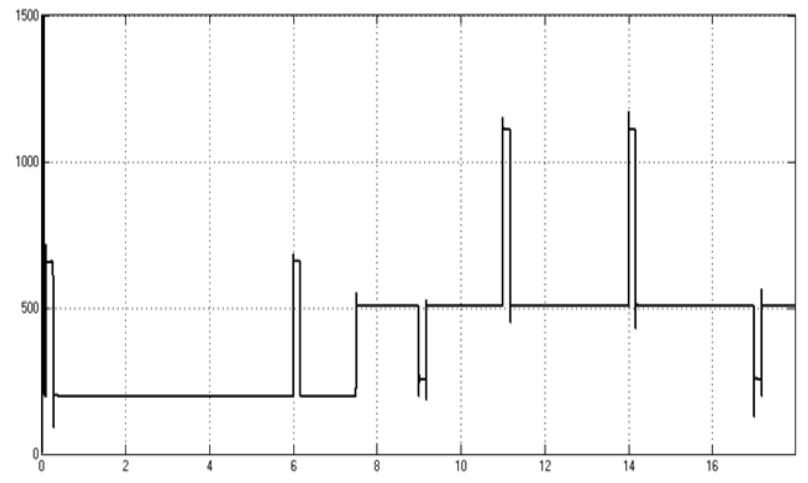

Fig. 16. The transient process of the stator current during the operating cycle of an asynchronous electric drive with vector control in the Matlab Simulink shell.

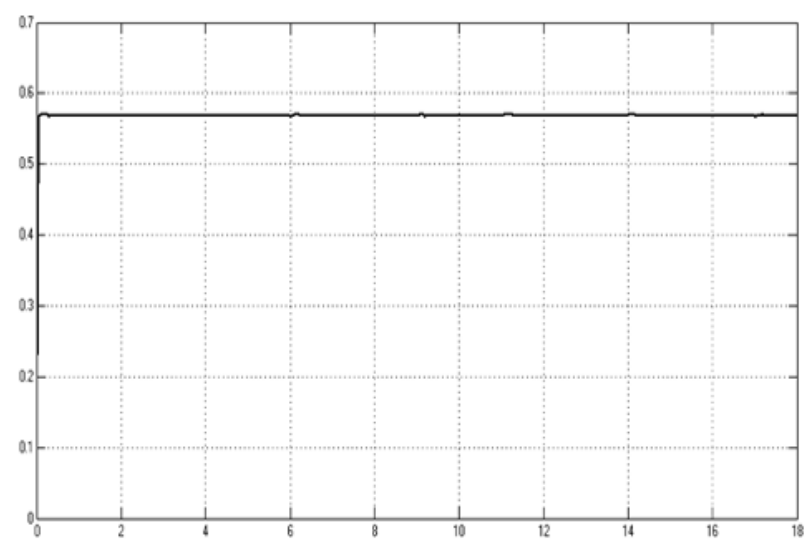

Fig. 17. Transient process of flux linkage during the working cycle of an asynchronous electric drive with vector control in the Matlab Simulink shell.

\section{Comparison of different types of PWM}

When lowering the slab, shock loads on roller tables or racks are inevitable. In the process of improving the systems for transporting slabs, the UPS-9 was able to store slabs on a turntable, which is a mechanism more sensitive to shock loads. There is a need for a smoother lowering of the slab onto the surface of the turntable, which can be done by setting a reduced reference for the speed of the electric drive when approaching the surface 
of the turntable. Using a sensor that will allow to identify the approach of the slab to the turntable, thereby activating the reduction of the set speed in the electric drive control system. The vector control system in this case, being more accurate in regulating the drive parameters and faster in comparison with systems with DCT, is the optimal solution to this problem. The need to limit accelerations and jerks, on the one hand, and the need to ensure the maximum performance of the UPS, on the other, requires that during transient processes the electric drive provides acceleration and deceleration of the lifting mechanism with the maximum allowable values of acceleration and jerk. The graphs are shown in Figures 18-24.

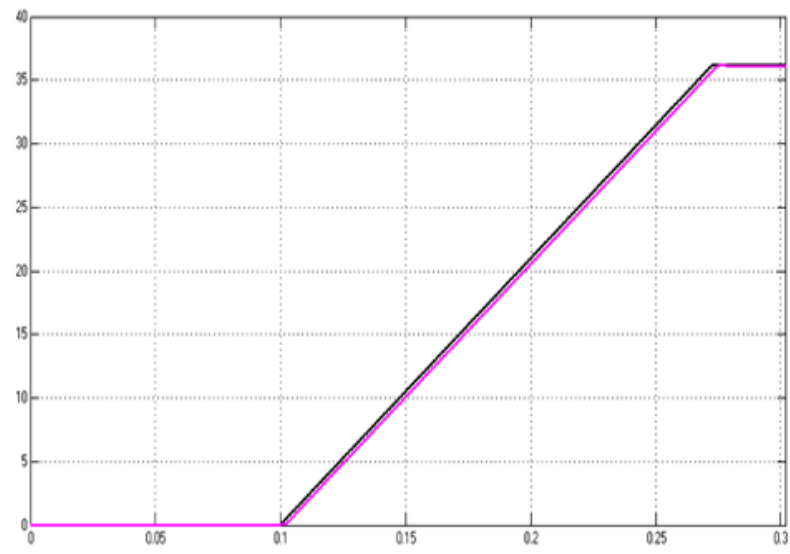

Fig. 18. Schedule for setting the speed at the output of the Sshaped ramp generator.

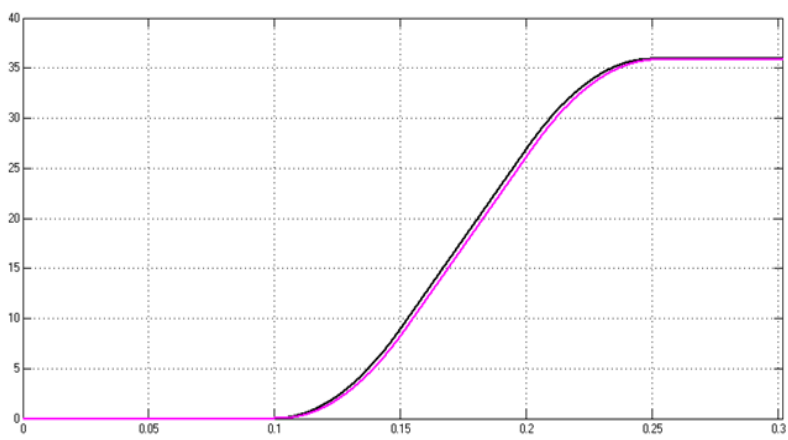

Fig. 19. Combined schedule of the speed reference from the $S$ shaped ZI and the speed of the electric drive.

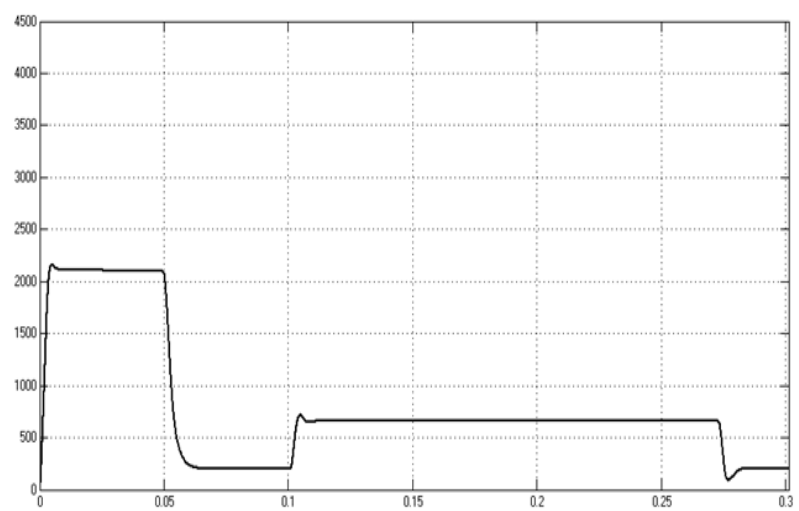

Fig. 20. The graph of the transient process of the stator current when the speed is set from the linear ZI.

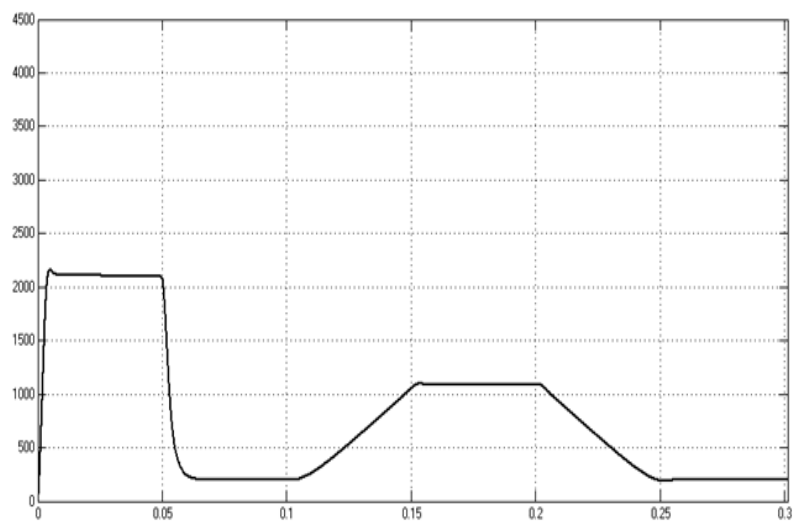

Fig. 21. The graph of the transient process of the stator current when the speed is set from the S-shaped ZI.

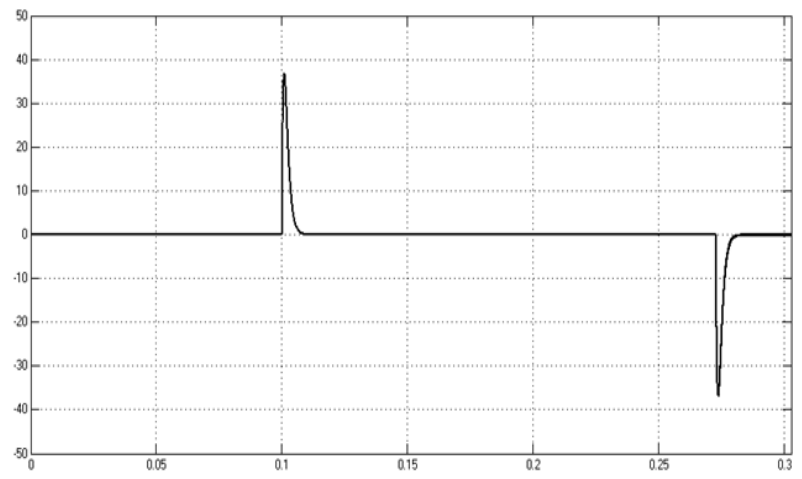

Fig. 22. The «jerk» graph when setting the speed from the linear ZI. 


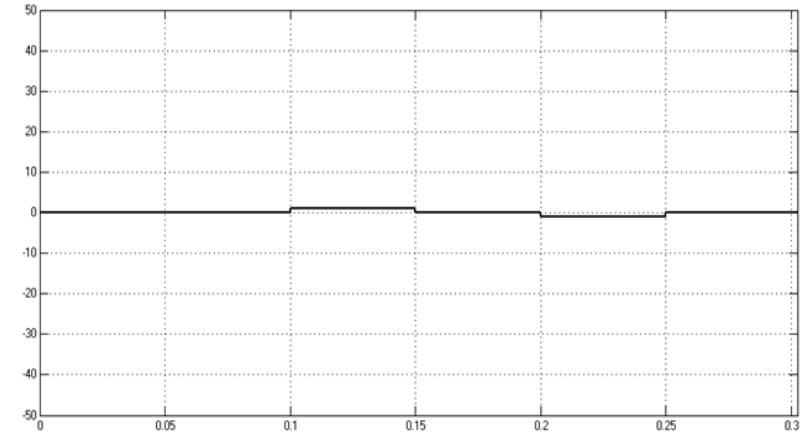

Fig. 23. The «jerk» graph when setting the speed from the Sshaped ZI.

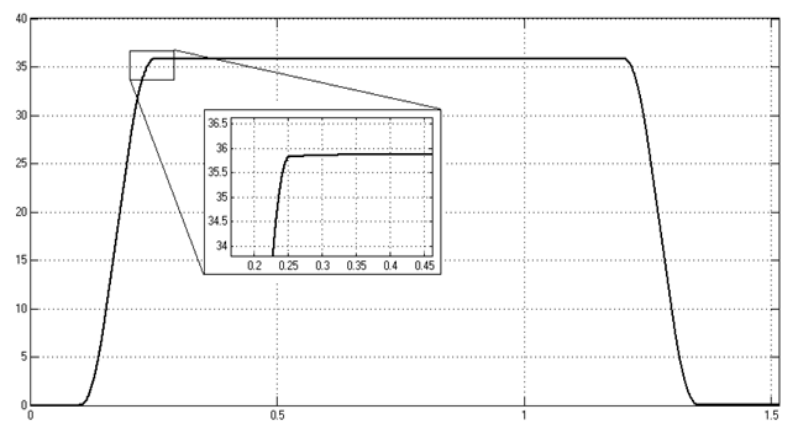

Fig. 24. Detailed graph of the transient process when setting the speed from the S-shaped ZI.

When analyzing the graphs obtained, a noticeable improvement in the quality of transient processes is observed in terms of the smoothness of reaching the specified characteristics. The proposed intensity generator provides the necessary limitation of accelerations and jerks, which makes it possible to reduce shock loads on the mechanical components of the electric drive, as well as on the rotary table when lowering the slab.

\section{Conclusion}

Mathematical modeling of the subordinate regulation system of the existing electric hoist drive system is carried out and the obtained transient processes are analyzed. Based on the study of the existing system, an asynchronous electric drive was chosen as the modernization of the electric drive for lifting slabs UPS9. The selected system of vector control of the electric drive was modeled, the graphs of transient processes were obtained and analyzed, and a variant was proposed to optimize the algorithm for lowering the slab to reduce the dynamic loads on the rotary table.

\section{References}

[1] V.N. Meshcheryakov, V.V. Danilov, Sh.R. Khasanov, S. Valtchev, Minimization of the stator current in induction motor with defined load on the shaft by maintaining optimum absolute slip, Kazan, SES 2019, E3S Web of Conferences, 01036 (2019)
[2] Y.I. Gracheva, N.A. Alimova, Calculating Methods and Comparative Analysis of Losses of Active and Electric Energy in Low Voltage Devices, International Ural Conference on Electrical Power Engineering (UralCon), 361-367 (2019)

[3] V.N. Meshcheryakov, D.V. Lastochkin, Z.M. Shakurova, S. Valtchev, Kazan, SES 2019, E3S Web of Conferences, 01037 (2019)

[4] Y.I. Gracheva, O.V. Naumov, Estimation of Power Losses in Electric Devices of the Electrotechnical Complex, International Conference on Industrial Engineering, Applications and Manufacturing (ICIEAM), 6 (2019)

[5] V. Meshcheryakov, T. Sinykova, A. Sinyukov, A. Boikov, R. Mukhametzhanov, Modeling and analysis of vector control systems for asynchronous motor, High Speed Turbomachines and Electrical Dreves Conference 2020 (HSTED-2020), Prague, Czech Republic, 01001 (9 July 2020)

[6] T.V. Sinykova, E.V. Sentsov, A.V. Sinyukov, Neural Network Speed Observers, Proceedings 2019 1st International Conference on Control Systems, Mathematical Modelling, Automation and Energy Efficiency (SUMMA), Lipetsk, Russia, 288 (2019)

[7] T.V. Sinykova, V.E. Gladyshev, A.V. Sinyukov, Methods for Reducing Electromechanical Oscillations in Conveyor Control Systems, Proceedings 2019 1st International Conference on Control Systems, Mathematical Modelling, Automation and Energy Efficiency (SUMMA), Lipetsk, Russia, 435 (2019)

[8] V. Meshcheryakov, D. Sibirtsev, E. Mikhailova, Mathematical Simulation of Synchronized Asynchronous Electric Drive, High Speed Turbomachines and Electrical Dreves Conference 2020 (HSTED-2020), Prague, Czech Republic, 01021 (9 July 2020)

[9] D.Yu. Kukishev, V.N. Meshcheryakov, V.N. Voyekov, I.V. Ivshin, Asynchronous electric drive with an additional switch in the DC link of the frequency converter, High Speed Turbomachines and Electrical Dreves Conference 2020 (HSTED2020), Prague, Czech Republic, 01043 (9 July 2020)

[10] Y.I. Gracheva, N.V. Chernova, A.I. Fedotov, E.A. Fedotov, Local Fourier transformation application for mathematic modeling of synchronous machine valve actuator, Journal of engineering and applied sciences 11, 1, 2939-2945 (2016)

[11] R.T.Y. Thien, Y. Kim, Decentralized Formation Flight via PID and Integral Sliding Mode Control, Aerospace Science and Technology, Elsevier Science Publishing Company, Inc. 81, 322-332 (2018)

[12] J. Fiser, P. Sitek, T. Vyhlidal, Neutral PID Control Loop Investigated in Terms of Similarity Theory, Ifac-Papersonline, Elsevier Science Publishing Company, Inc. 51, 14, 212-217 (2018) 
[13] J. Fiser, P. Sitek, T. Vyhlidal, Robust PID Controller Design for Plants With Delay Using Similarity Theory, Ifac-Papersonline, Elsevier Science Publishing Company, Inc. 51, 14, 236-241 (2018)

[14] L.D.S. Coelho, A.A.R. Corlho, Automatic Tuning of PID and Gain Scheduling PID Controllerrs by a Derandomized Evolution Strategy, Ai Edem. Cambridge University Press 13, 5, 341-349 (1999)

[15] Z. Hu, Y.V. Bodyanskiy, O.K. Tyshchenko, A Multidimensional Adaptive Growing Neuro-Fuzzy System and Its Online Learning Procedure, Advances in Intelligent System and Computing 689, 186-203 (2018) 